\title{
Intracranial Electrophysiology Reveals Reproducible Intrinsic Functional Connectivity within Human Brain Networks
}

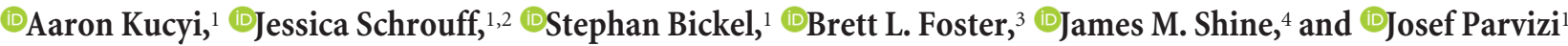 \\ ${ }^{1}$ Department of Neurology and Neurological Sciences, Stanford University, Stanford, California 94304, ${ }^{2}$ Centre for Medical Image Computing, Department \\ of Computer Science, University College London, London WC1E 6BT, United Kingdom, ${ }^{3}$ Departments of Neurosurgery and Neuroscience, Baylor College of \\ Medicine, Houston, Texas 77030, and ${ }^{4}$ Brain and Mind Center, The University of Sydney, Sydney, New South Wales 2050, Australia
}

Evidence for intrinsic functional connectivity (FC) within the human brain is largely from neuroimaging studies of hemodynamic activity. Data are lacking from anatomically precise electrophysiological recordings in the most widely studied nodes of human brain networks. Here we used a combination of fMRI and electrocorticography (ECoG) in five human neurosurgical patients with electrodes in the canonical "default" (medial prefrontal and posteromedial cortex), "dorsal attention" (frontal eye fields and superior parietal lobule), and "frontoparietal control" (inferior parietal lobule and dorsolateral prefrontal cortex) networks. In this unique cohort, simultaneous intracranial recordings within these networks were anatomically matched across different individuals. Within each network and for each individual, we found a positive, and reproducible, spatial correlation for FC measures obtained from resting-state fMRI and separately recorded ECoG in the same brains. This relationship was reliably identified for electrophysiological FC based on slow $(<1 \mathrm{~Hz})$ fluctuations of high-frequency broadband $(70-170 \mathrm{~Hz})$ power, both during wakeful rest and sleep. A similar FC organization was often recovered when using lower-frequency $(1-70 \mathrm{~Hz})$ power, but anatomical specificity and consistency were greatest for the high-frequency broadband range. An interfrequency comparison of fluctuations in $\mathrm{FC}$ revealed that high and low-frequency ranges often temporally diverged from one another, suggesting that multiple neurophysiological sources may underlie variations in FC. Together, our work offers a generalizable electrophysiological basis for intrinsic FC and its dynamics across individuals, brain networks, and behavioral states.

Key words: default mode network; dorsal attention network; dynamic functional connectivity; electrocorticography; resting-state fMRI

Significance Statement

The study of human brain networks during wakeful "rest", largely with fMRI, is now a major focus in both cognitive and clinical neuroscience. However, little is known about the neurophysiology of these networks and their dynamics. We studied neural activity during wakeful rest and sleep within neurosurgical patients with directly implanted electrodes. We found that network activity patterns showed striking similarities between fMRI and direct recordings in the same brains. With improved resolution of direct recordings, we also found that networks were best characterized with specific activity frequencies and that different frequencies show different profiles of within-network activity over time. Our work clarifies how networks spontaneously organize themselves across individuals, brain networks, and behavioral states.

\section{Introduction}

The study of spontaneous brain activity has recently emerged as a major focus in both cognitive and clinical neuroscience (Fox and Raichle, 2007; Buckner et al., 2013). During so-called "restingstate” fMRI (rs-fMRI; Biswal et al., 1995), remote regions within the human brain are coordinated over time, demonstrating per-

Received Jan. 25, 2018; revised March 3, 2018; accepted March 31, 2018.

Author contributions: A.K., J.M.S., and J.P. wrote the first draft of the paper; A.K., J.S., S.B., B.F., J.M.S., and J.P. edited the paper; A.K., J.S., S.B., B.F., and J.P. designed research; A.K., J.S., S.B., B.F., and J.P. performed research; A.K., J.S., S.B., B.F., and J.M.S. analyzed data; A.K., J.M.S., and J.P. wrote the paper. sistent, correlated activity [functional connectivity (FC)]. Networks derived from ultraslow $(<0.1 \mathrm{~Hz})$ blood oxygenation level-dependent (BOLD) signals are described as "intrinsic" because their spatial organization is remarkably similar (with minor modulation) across diverse mental states, including wakeful rest, task performance, and altered consciousness during sleep and 
general anesthesia (Vincent et al., 2007; Larson-Prior et al., 2009; Schrouff et al., 2011; Cole et al., 2014). It has been hypothesized that intrinsic FC is constrained by monosynaptic and polysynaptic anatomical connectivity pathways (Honey et al., 2009; Lu et al., 2011; Roland et al., 2017; Shine et al., 2017), mirrors patterns of task-evoked coactivation (Smith et al., 2009; Mennes et al., 2010; Tavor et al., 2016), and serves a fundamental role in maintaining the brain's network-level organization (Raichle, 2015).

To date, reservations remain in the field about the inherent value of studying intrinsic FC with fMRI. Estimates of FC can be severely affected by respiratory and cardiac activity (Birn et al., 2008; Chang and Glover, 2009) as well as head motion (Power et al., 2012; Van Dijk et al., 2012) and sampling variability (Handwerker et al., 2012; Laumann et al., 2017). Intracranial electroencephalography (iEEG), based on directly implanted electrodes for neurosurgical purposes, offers a means to validate and investigate the potential neural basis of BOLD FC. A rich literature suggests that increased high-frequency broadband (HFB; 70-170 Hz) power amplitude in iEEG recordings serves as an effective index of local population spiking and is associated with evoked and spontaneous BOLD activity (Logothetis et al., 2001; Mukamel et al., 2005; Liu and Newsome, 2006; Nir et al., 2007; Manning et al., 2009; Ray and Maunsell, 2011).

A candidate electrophysiological marker of BOLD FC is the correlation of slow $(<1 \mathrm{~Hz})$ fluctuations in the power amplitude (the signal "envelope") of HFB, and possibly other frequency ranges (Engel et al., 2013; Foster et al., 2016). Initially in monkeys, Leopold et al. (2003) demonstrated that band-limited envelope signals have persistent inter-regional interactions across diverse behavioral states. In the human brain, Nir et al. (2008) then showed persistent $40-100 \mathrm{~Hz}$ slow envelope FC between the right and left human auditory cortex during wakeful rest and sleep. Subsequently, within patients who underwent rs-fMRI before or after surgery, others found that iEEG and BOLD FC patterns were spatially correlated with one another within the same individuals (He et al., 2008; Keller et al., 2013; Foster et al., 2015; Hacker et al., 2017). Although these past studies have provided invaluable information from intracranial recordings that were either within single subnetworks (He et al., 2008; Foster et al., 2015) or with different within-network regions covered in each subject (Keller et al., 2013; Hacker et al., 2017), a systematic analysis of FC using electrophysiological and BOLD data across individuals, networks, and behavioral states has been missing.

To address the existing gap of knowledge, we investigated a unique cohort of neurosurgical patients with intracranial electrode coverage within key, cross-individual matched, nodes of "default mode" network (DMN), "dorsal attention" netwokr (DAN), and "frontoparietal control" network (FPCN) networks, which have been most frequently studied with neuroimaging methods. We used intracranial recordings across multiple individuals and across behavioral states and examined FC patterns using different bands of electrophysiological activity. Finally, given that organized FC patterns could be found for different frequency ranges, we examined whether all frequency bands of electrophysiological activity followed the same or different dy-

B.L.F. was supported by a research grant from the U.S. National Institute of Mental Health (R00MH103479).

The authors declare no competing financial interests.

Correspondence should be addressed to Dr. Aaron Kucyi, Department of Neurology and Neurological Sciences,

Stanford University Medical Center, 300 Pasteur Drive, Alway Building M030, Stanford, CA 94304. E-mail: akucyi@stanford.edu.

DOI:10.1523/JNEUROSCI.0217-18.2018

Copyright $\odot 2018$ the authors $\quad 0270-6474 / 18 / 384231-13 \$ 15.00 / 0$ namic changes on short time scales (arguing for a common or different neurophysiological source).

\section{Materials and Methods}

General approach. To achieve the aims of our study, we first identified electrocorticography (ECoG) electrode locations that fell within intrinsic networks as defined in fMRI within subjects. When comparing FC in fMRI versus intracranial EEG, mismatches could arise due to genuine differences, but also due to technical reasons including (1) misaligned registration of an electrode location to the fMRI scan, (2) fMRI signal dropout at an electrode location, (3) artifacts in the ECoG signal from medical devices (e.g., IV pumps), (4) differences in spatial resolution captured by an ECoG electrode and a region-of-interest in fMRI, or (5) a mixture of signals from distinct networks at the electrode location in ECoG or in fMRI. Moreover, ECoG and fMRI FC could spuriously appear similar, particularly between short distances, because of biases in each modality (volume conduction between proximal locations in ECoG, spatial autocorrelation in $\mathrm{PMRI}$ ).

We therefore focused exclusively on cases in which there was a reproducible match between modalities that we could confidently attribute to genuine similarity between ECoG and fMRI. We focused on electrode positions that were within well described intrinsic networks, were physically distant from each another (in different lobes), and showed spatially-specific fMRI versus ECoG (HFB envelope) correspondence that was reproducible from more than one ECoG recording.

Subject selection. Data from five human subjects (S1-S5) with refractory epilepsy, who were undergoing neurosurgical treatment at Stanford University Medical Center, were included in analyses (age range: 22-63, 4 females and 1 male, all right-handed; for full demographic and other details, see Table 1). Subjects were implanted with subdural intracranial electrodes (over the left hemisphere in 4 subjects and right hemisphere in 1 subject), with placement decided based on clinical evaluation for resective surgery. Subjects provided verbal and written consent to participate in research, and the Stanford Institutional Review Board approved all procedures described herein.

When planning our analyses, we reviewed 14 total subjects for potential inclusion. These subjects had all undergone subdural ECoG recordings as well as preoperative or postoperative rs-fMRI. We ended up with a sample of five patients based on the following inclusion criteria: (1) simultaneous ECoG coverage in the two nodes of interest within at least one of the three networks of interest, defined as posteromedial cortex and medial prefrontal cortex (DMN), frontal eye fields and superior parietal lobule (DAN), or dorsolateral prefrontal cortex and anterior inferior parietal lobule (FPCN; 7 excluded); (2) absence of ECoG signal indicative of noise or pathology during resting-state recordings within electrodes of interest (see ECoG Preprocessing 1 excluded); and (3) an acceptable level of head motion in fMRI (mean relative head displacement $<0.2 \mathrm{~mm}$; 1 excluded). Independent analyses of data from two of the patients presented here have been published previously (Foster et al., 2015).

ECoG acquisition. Intracranial recordings were obtained at bedside of the subject's private clinical suite. Platinum electrodes (Adtech Medical Instruments) were embedded in a flexible silicon sheet and were arranged in grid or strip configurations. Each electrode had a diameter of $2.3 \mathrm{~mm}$ in the exposed area of recording. Inter-electrode spacing was either $10 \mathrm{~mm}$ (center to center) or $5 \mathrm{~mm}$. The resting-state ECoG data were acquired with a multichannel research system (Tucker Davis Technologies) with a bandpass filter of $0.5-300 \mathrm{~Hz}$ and a sampling rate of either $3052 \mathrm{~Hz}$ (S1, S2, S3) or $1526 \mathrm{~Hz}$ (S4, S5). During recording, the ECoG signals were referenced to the most electrographically silent channel outside of the seizure focus. The total number of electrode sites ranged from 108 to 144 (mean $\pm \mathrm{SD}=123.2 \pm 19.7$ ). For one subject (S3), a recording during sleep $(4.76 \mathrm{~min})$ was collected with a clinical monitoring system (Nihon Kohden). This recording was during stage 2/3 of sleep, as reported previously (Foster et al., 2015). The same reference montage was used for the sleep recording, but the sampling rate was different $(500 \mathrm{~Hz})$.

Two resting-state ECoG recordings were acquired, each at a separate time (usually a different day) for each subject. Before each resting-state 
Table 1. Subject demographics and characteristics

\begin{tabular}{|c|c|c|c|c|c|}
\hline & S1 & S2 & S3 & S4 & S5 \\
\hline Age & 63 & 36 & 22 & 34 & 38 \\
\hline Sex & $\mathrm{F}$ & $\mathrm{F}$ & $\mathrm{F}$ & M & $\mathrm{F}$ \\
\hline Implanted Hemisphere & Left & Left & Left & Right & Left \\
\hline Epileptic focus & $\begin{array}{l}\text { Orbitofrontal and medial } \\
\text { temporal lobe }\end{array}$ & $\begin{array}{l}\text { Primary } \\
\text { motor }\end{array}$ & $\begin{array}{l}\text { Mesial frontal spikes } \\
\text { (exact focus unknown) }\end{array}$ & $\begin{array}{l}\text { Dorsolateral } \\
\text { frontal }\end{array}$ & $\begin{array}{l}\text { Primary } \\
\text { motor }\end{array}$ \\
\hline Duration of epilepsy, years & 52 & 9 & 2 & 20 & 14 \\
\hline ECoG Rest 1 instruction & Eyes closed & Eyes closed & Eyes closed & Eyes closed & Eyes closed \\
\hline ECoG Rest 1 duration, min & 6.14 & 4.2 & 9.92 & 4.24 & 7.27 \\
\hline Rest 1: no. of electrodes analyzed/total & $90 / 108$ & $86 / 122$ & $72 / 100$ & $103 / 142$ & $121 / 144$ \\
\hline ECoG Rest 2 instruction & Eyes open & Eyes open & Eyes open & None & Eyes closed \\
\hline ECoG Rest 2 duration, min & 2.16 & 4.81 & 4.85 & 5.31 & 7.60 \\
\hline Rest 2: no. of electrodes analyzed/total & $91 / 108$ & $84 / 122$ & $68 / 100$ & $100 / 142$ & $110 / 144$ \\
\hline fMRI duration, min & 6.0 & 8.0 & 10.0 & 10.0 & 8.0 \\
\hline fMRI mean frame-wise displacement, $\mathrm{mm}$ & 0.15 & 0.06 & 0.04 & 0.08 & 0.1 \\
\hline
\end{tabular}

recording, subjects were instructed to relax and not think of anything in particular while either keeping eyes open or closed (Table 1). For one run in one subject (S4), no instruction was given, but the subject was not explicitly engaged with a task during the recording. The individual resting-state runs were recorded during periods that were free of interictal discharges and ranged in duration between 2.16 and 9.92 $\min$ (Table 1).

MRI acquisition. In an MRI session that was either preoperative (S1, S2, S4, S5) or postoperative (S3), subjects underwent structural MRI (T1-weighted) and fMRI $\left(\mathrm{T} 2^{*}\right)$. Neuroimaging was performed on a $3 \mathrm{~T}$ GE scanner equipped with a 32-channel head coil, either at Richard M. Lucas Center for Imaging (S5) or Center for Cognitive and Neurobiological Imaging (S1, S2, S3, and S4). During rs-fMRI, subjects were instructed to not think about anything in particular. The fMRI scan duration was $6 \mathrm{~min}(\mathrm{~S} 1), 8 \mathrm{~min}(\mathrm{~S} 2, \mathrm{~S} 5)$, or $10 \mathrm{~min}(\mathrm{~S} 3, \mathrm{~S} 4)$. Parameters were $64 \times 64 \mathrm{~mm}$ matrix, $3.3 \times 3.3 \times 4 \mathrm{~mm}(\mathrm{~S} 2, \mathrm{~S} 3, \mathrm{~S} 4, \mathrm{~S} 5)$ or $3.3 \mathrm{~mm}$ isotropic (S1) voxels, $210 \mathrm{~mm}$ (S1, S2, S4, S5) or $220 \mathrm{~mm}$ (S1) field-ofview, 36 slices (S2, S3, S4, S5) or 30 slices (S1), 2 s repetition time, $77^{\circ}$ flip angle, and $30 \mathrm{~ms}$ echo time. For the T1 scan, the parameters were as follows: $256 \times 256$ matrix, 186 slices, $0.90 \times 0.90 \times 0.90 \mathrm{~mm}$ voxels, 240 mm field-of-view, $7.60 \mathrm{~ms}$ TR.

Electrode localization. Electrodes were localized on the cortical surface using procedures implemented in the iELVis toolbox (Groppe et al., 2017). First, the $\mathrm{T} 1 \mathrm{scan}$ was processed and automatically segmented in FreeSurfer v6.0 (recon-all command) to reconstruct the pial, leptomeningeal, and inflated cortical surfaces (Fischl et al., 1999). A post-implant CT image was spatially registered to the space of the higher resolution T1 scan using a rigid transformation (6 degrees-of-freedom, affine mapping). Using BioImage Suite (), we manually labeled the electrode locations on the T1-registered CT image. The electrode locations were then projected to the leptomeningeal surface to correct for possible postimplant brain shift, using an iterative optimization algorithm (Dykstra et al., 2012). The resulting individual surface and volume coordinates were used for visualization and analyses described below.

ECoG preprocessing. Each ECoG run was preprocessed individually with publicly available tools from a MATLAB pipeline developed inhouse () that draws from functions for electrophysiological signal processing in SPM12 (Kiebel and Friston, 2004) and Fieldtrip (Oostenveld et al., 2011). Signals were first downsampled to $1000 \mathrm{~Hz}$ (for runs where the sampling rate was $>1000 \mathrm{~Hz}$ ). Next, notch filtering was performed to remove line noise at 60,120 , and $180 \mathrm{~Hz}$. We then performed common averaging re-referencing, excluding from the average the electrodes that either (1) showed pathological activity during clinical monitoring (as noted by a neurologist); (2) had a variance greater than five times, or less than five divided by the median variance across all electrodes; or (3) was "spikey" (i.e., had $>3$ times the median number of spikes across all electrodes, with spikes defined as $100 \mu \mathrm{V}$ changes between successive samples).

Following re-referencing, we performed time-frequency decomposition for estimation of power spectra, using Morlet transform with five wavelet cycles and with frequencies of interest log-spaced between 1 and
$170 \mathrm{~Hz}$ ( 38 total values). The decomposition was then rescaled by the log ratio to normalize the distributions of power amplitude estimates at each frequency of interest. We then averaged the power amplitude estimates (envelopes) within seven canonical frequency bands: delta $(1-3 \mathrm{~Hz})$, theta $(4-7 \mathrm{~Hz}), \alpha(8-12 \mathrm{~Hz})$, betal $(13-29 \mathrm{~Hz})$, beta2 $(30-39 \mathrm{~Hz})$, gamma $(40-70 \mathrm{~Hz})$, and HFB $(70-170 \mathrm{~Hz})$. Finally, motivated by previous findings linking ECoG with BOLD FC (Keller et al., 2013; Foster et al., 2015), a 0.1-1 Hz bandpass filter (Butterworth, fourth-order) was applied to each frequency band. We also performed analyses with a lowpass filter of $<0.1 \mathrm{~Hz}$ on the envelope signals, but because some of the run durations were $<5 \mathrm{~min}$, the number of cycles investigated was suboptimal when applying this filter, and we thus mainly focus on the $0.1-1$ $\mathrm{Hz}$ filtered data. We $Z$-score normalized the HFB power amplitudes within each run (subtracted out mean then divided by SD) and visually inspected each electrode for outlier time points or seizure-like events. We excluded from analysis all electrodes that had any samples with a $Z$-score $>8$ in the HFB signal or showed other signs of irregular or pathological activity. After exclusion, an average of $75 \%$ of electrodes were retained within a given run (Table 1 ).

fMRI preprocessing. We first manually inspected fMRI data for excessive head motion or artifacts by viewing each volume. The mean relative head displacement values for included subjects (S1-S5) were 0.15, 0.06, $0.04,0.08$, and $0.1 \mathrm{~mm}$. Preprocessing was performed on fMRI data using tools from FSL (Jenkinson et al., 2012), MATLAB, FreeSurfer, and fMRISTAT (Worsley et al., 2002). For the main analysis, preprocessing began with deletion of the first four acquired volumes, brain extraction (BET), motion correction (i.e., volume realignment) with FSL's MCFLIRT, and linear registration ( 6 degrees-of-freedom, fMRI to T1weighted image). Data were automatically segmented into white matter (WM), CSF, and gray matter (GM) using FSL's FAST applied to the T1-weighted scan, and these segments were registered to fMRI space. The segments were then eroded to retain the top $198 \mathrm{~cm}^{3}$ and top $20 \mathrm{~cm}^{3}$ of voxels with highest probability of being WM and CSF, respectively, to avoid overlap with GM signal (Chai et al., 2012). The mean global brain signal, mean WM signal, mean CSF signal, and six motion parameters obtained with MCFLIRT were regressed out of each voxel. We then performed spatial smoothing ( $6 \mathrm{~mm}$ full-width at half-maximum kernel) and temporal filtering $(0.01-0.1 \mathrm{~Hz})$.

There remains no consensus on the most appropriate way to preprocess fMRI data before FC analysis (Ciric et al., 2017). We choose to report our main results from the preprocessing described above (global signal regression pipeline) because of previously demonstrated improved ECoG-fMRI correspondence using similar methods (Keller et al., 2013). However, we also performed preprocessing with two alternative pipelines to confirm the main results.

The first alternative pipeline included the "aCompCor approach" (Behzadi et al., 2007). The aCompCor pipeline followed the same procedures as the global signal regression pipeline until after erosion of WM and CSF volumes. Principal components analysis of fMRI time series was then applied to the WM and CSF volumes, and top five components from 
each segment were regressed from each voxel. Subsequently, the six motion parameters were regressed out, and spatial and temporal filtering were performed as described above.

The second alternative pipeline included the "ICA-AROMA" approach (Pruim et al., 2015). Preprocessing proceeded with the following steps: deletion of the first 4 volumes, brain extraction, motion correction, spatial smoothing ( $6 \mathrm{~mm}$ kernel), and nonlinear registration of fMRI with T1 image and MNI152 standard spaces. Independent components analysis (ICA) with FSL's MELODIC and automatic dimensionality estimation was then applied. Automatically labeled components that had indicators of predominantly non-neural signal were then regressed out of each voxel (Pruim et al., 2015). The signals from WM and CSF segments were then regressed out. Finally, bandpass temporal filtering (0.01-0.1 $\mathrm{Hz}$ ) was performed.

ECoG-HFB versus BOLD FC analysis. Using the electrode coordinates in fMRI volume space, as obtained after correction for postimplant brain shift, we extracted the time series from a $6 \mathrm{~mm}$ radius sphere at each electrode location. Using each electrode as a seed region, we then calculated seed-based FC with all other electrodes, defined as the Pearson correlation coefficient $(r)$ of the time series converted to $z$ using the Fisher transformation. Similarly, in ECoG, we calculated seed-based FC for each electrode, at first using the bandpass-filtered $(0.1-1 \mathrm{~Hz}) \mathrm{HFB}$ envelope signal.

Using one of the two resting-state ECoG runs as the discovery dataset, we visually compared seed-based ECoG with BOLD FC spatial patterns from seed regions suspected to be within key nodes of the networks of interest, similar to procedures described by Braga and Buckner (2017). For visualization purposes, in BOLD we computed seed-based FC with the whole brain using a general linear model with the seed region's demeaned time series entered as a regressor in FSL. The volume map of $Z$-scores obtained at each voxel was then projected to vertices on the cortical surface in FreeSurfer. Using iElvis, we overlaid the ECoG FC values at the electrode locations on the cortical surface map displaying BOLD FC at each vertex location.

Guided by intrinsic network anatomy from functional neuroimaging in healthy populations (Power et al., 2011; Yeo et al., 2011), for each network in a given patient, we identified a single electrode location that appeared to show high, and spatially specific FC with a predefined target node of interest within the network. The pair nodes of interest were mPFC-PMC (for DMN), SPL-FEF (for DAN), and dlPFC-aIPS (for FPCN). To formally assess the similarity between ECoG and BOLD FC, in both the discovery and replication (second ECoG resting-state run) datasets, we performed a spatial correlation between seed-based BOLD and ECoG FC from the selected electrode location (i.e., a correlation of FC values at all target electrodes; significance set at $p<0.05$ in the replication cohort). We additionally performed partial correlations between seed-based BOLD and ECoG FC, controlling for Euclidean distance between the seed and each target electrode. Moreover, we performed BOLD versus ECoG FC spatial correlations using BOLD data preprocessed with the alternative pipelines of aCompCor and ICA-AROMA.

For each seed electrode, we identified an electrode in the withinnetwork target node of interest that showed strong HFB envelope FC with the seed (defined as having FC with the seed that was within at least the top 10 percentile of all target electrodes, after averaging FC values across the 2 ECoG runs). For within-network seed-target electrode pairs, we computed interelectrode cross-correlations between their HFB envelope time series (random order for each pair), with shifts ranging from -5 to $+5 \mathrm{~s}$ (using the longer of the $2 \mathrm{ECoG}$ runs in each subject). We calculated the average lag across intranetwork electrode pairs of the peak absolute correlation coefficients.

ECoG: wakeful rest and sleep comparison. In one subject (S3) who uniquely had electrode coverage within both nodes of interest within the three networks of interest (DMN, DAN, and FPCN), we compared ECoG-HFB envelope FC at rest (2 independent runs) versus sleep (2 run). Using the previously defined seed electrodes of interest, we performed spatial correlations of seed-based HFB envelope FC between wakeful rest and sleep states (significance set at $p<0.05$ ). Moreover, we performed spatial correlations of sleep versus resting-state BOLD FC (significance set at $p<0.05$ ).

ECoG: FC of multiple frequencies. Following our initial analyses focusing on FC of HFB envelope signals, we performed a comprehensive analysis of other frequency ranges. As in the HFB and BOLD analyses, we calculated seed-based FC of the envelopes of delta, theta, $\alpha$, beta1, beta2, and gamma activity (averaged between the 2 ECoG resting-state runs). Across the within-network region pairs (as previously defined based on HFB envelope FC), we performed a repeated-measures ANOVA to test whether there was a significant interaction between FC (Fisher- $z$ transformed value) and frequency (significance set at Huyn Feldt $p<0.05$ ). Additionally, we performed spatial correlations of seed-based FC for all frequency ranges versus BOLD FC (with and without correction for $\mathrm{Eu}$ clidean distance) as well as for each frequency range versus every other frequency range (i.e., a $7 \times 7$ correlation matrix). We performed a repeated-measures ANOVA to test whether there was a significant interaction between ECoG frequency of FC and magnitude of the BOLDECoG spatial correlation (Fisher- $z$ transformed value; significance set at Huyn Feldt $p<0.05$ ).

ECoG: dynamic connectivity analysis. We performed dynamic connectivity analyses on the longer of the two ECoG resting-state runs in a given patient. Focusing on previously defined within-network region pairs, in each temporal window, we computed the Pearson correlation coefficient between the electrodes' time series. Starting from the beginning and until the end of the run, we progressively shifted the window by $50 \%$ of the total window length, and then recalculated the correlation to obtain a sliding-window correlation time series. Based on the recommendations of Leonardi and Van De Ville (2015), and to match the time scale of dynamic FC of frequency-specific envelopes presented in previous MEG studies (de Pasquale et al., 2010, 2012), we present main results for a $10 \mathrm{~s}$ window length (the reciprocal of the slowest frequency component, i.e., $0.1 \mathrm{~Hz})$.

The dynamic FC analyses were performed on the $0.1-1 \mathrm{~Hz}$ filtered envelope signals in the same manner for each of the seven frequency ranges of interest. To assess whether there were similar or diverging intranetwork envelope FC fluctuations among different frequencies, for given pair of regions, we performed interfrequency temporal correlations of FC (Fisher $-z$ transformed values). This resulted in a $7 \times 7$ correlation matrix. Importantly, these tests only assess whether there was statistical dependence of FC fluctuations between different frequencies for the same pair of regions and do not enable inferences about whether nonstationarity was present in a given sliding-window correlation time course (Liégeois et al., 2017).

\section{Results \\ Unique intracranial recordings within intrinsic human brain networks}

We studied five patients with focal epilepsy who had ECoG electrodes implanted subdurally for clinical purposes (Table 1). We focused on regions that did not show pathological activity. Guided by intrinsic network anatomy from functional neuroimaging in healthy populations (Power et al., 2011; Yeo et al., 2011), we identified multisite electrode coverage within the anatomical boundaries of networks of interest using the same individuals' fMRI data (Fig. $1 A, C, D$ ). We focused on patients who had multisite recordings within two major, predefined nodes of at least one of the DMN, DAN, or FPCN. Thus, recordings were anatomically matched across individuals within each given network.

Three subjects (S1-S3) had multisite recordings within the medial prefrontal cortex (mPFC) and posteromedial cortex (PMC), known to be the core nodes within the DMN (Raichle et al., 2001; Greicius et al., 2003; Andrews-Hanna et al., 2010). Two subjects $(\mathrm{S} 3, \mathrm{~S} 4)$ had simultaneous coverage within the frontal eye fields (FEF) and superior parietal lobule (SPL), key regions within the DAN (Corbetta and Shulman, 2002; Fox et al., 2006). Two subjects $(\mathrm{S} 3, \mathrm{~S} 5)$ had coverage within the dorsolateral prefrontal cortex (dlPFC) and anterior inferior parietal lobule 
A S1

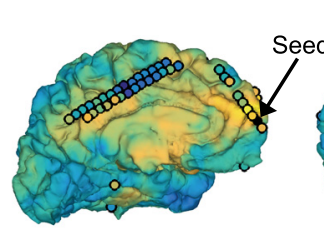
S2

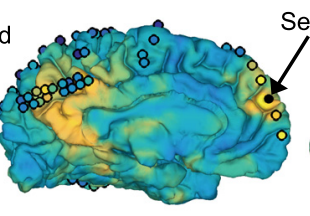
Seed
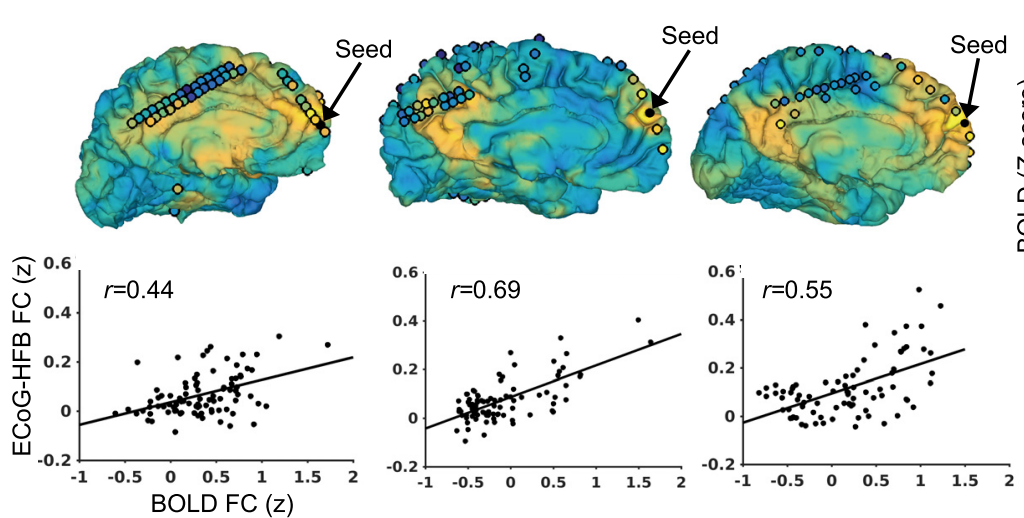
Connectivity
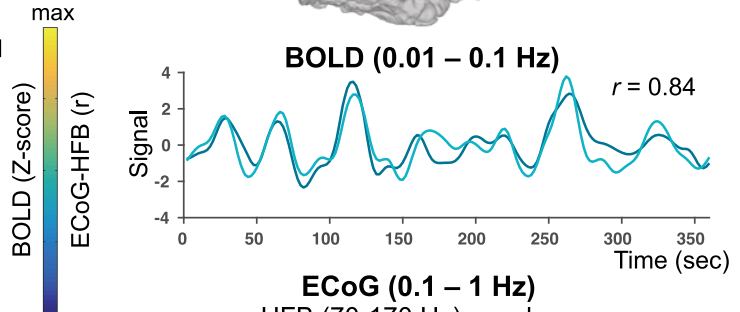

ECoG (0.1 - $1 \mathrm{~Hz})$

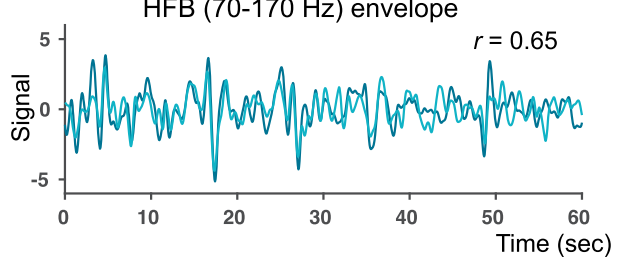

C

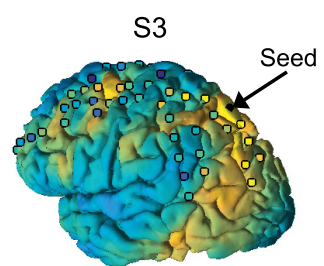

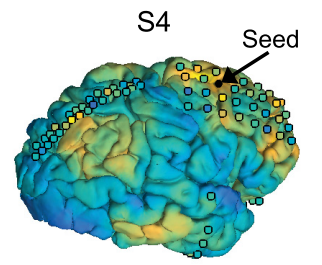

D Frontoparietal Control Network
S3

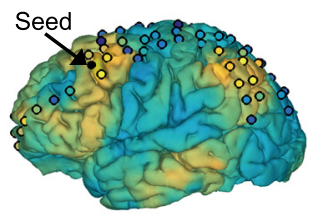

S5

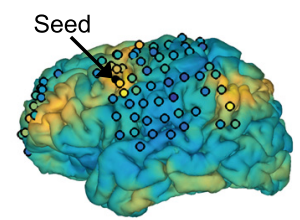

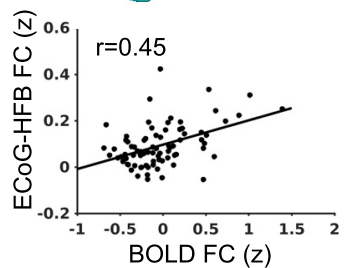
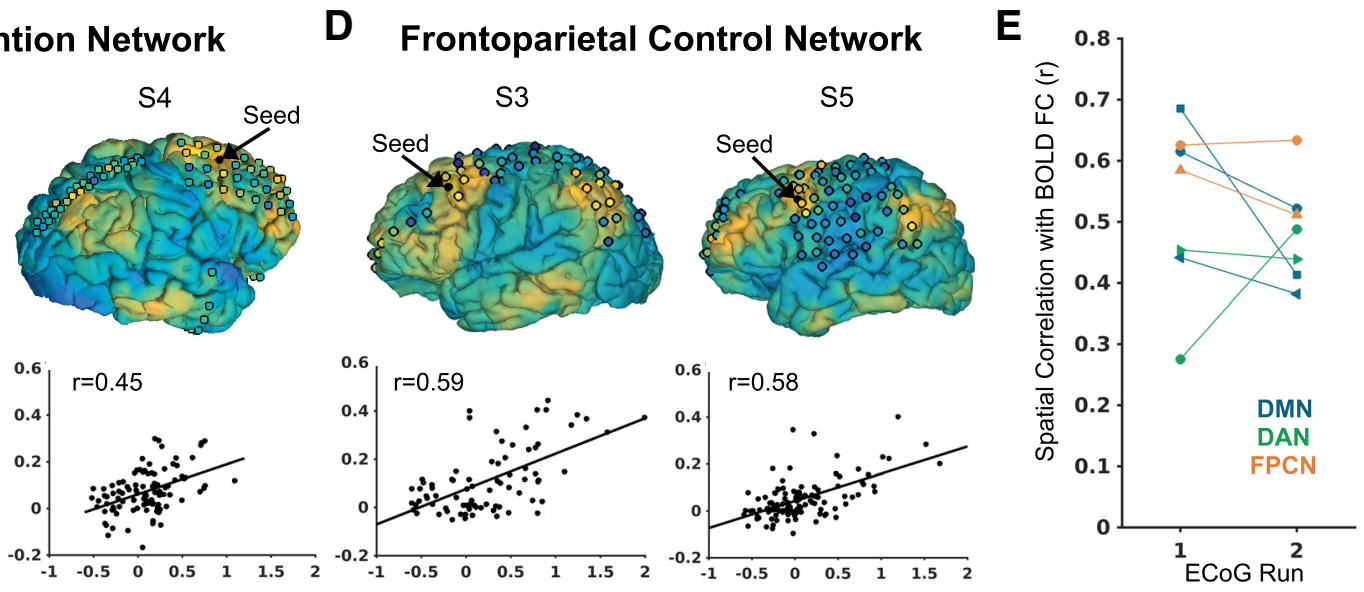

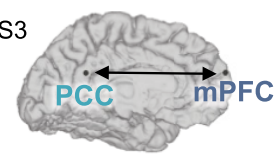

B

$r=0.65$
$\mathbf{F}$ S3

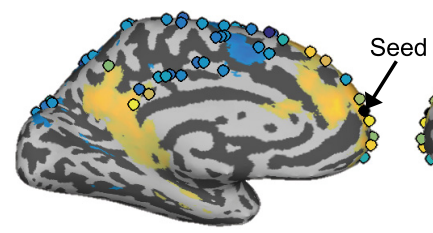

ECoG Run 1 versus fMRI

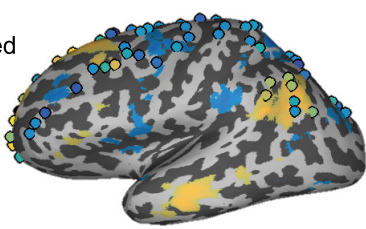

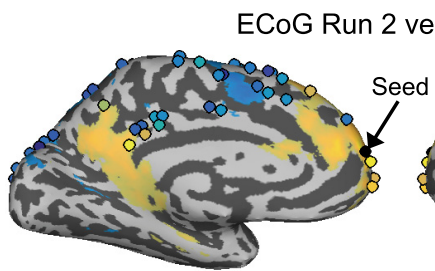



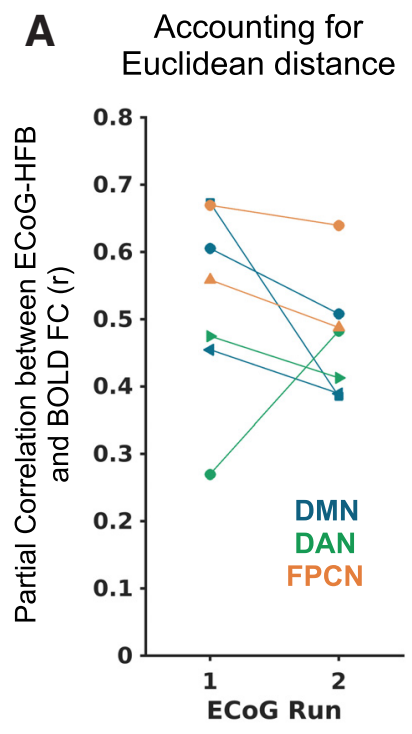

B Effect of BOLD Preprocessing

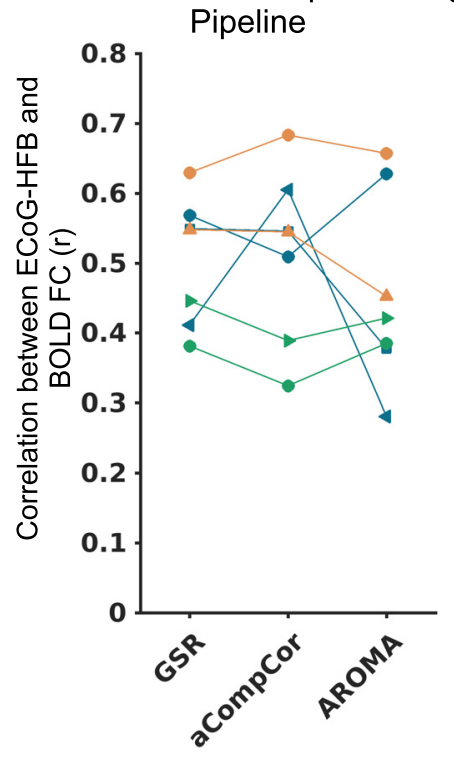

C

$<0.1 \mathrm{~Hz}$ Envelope

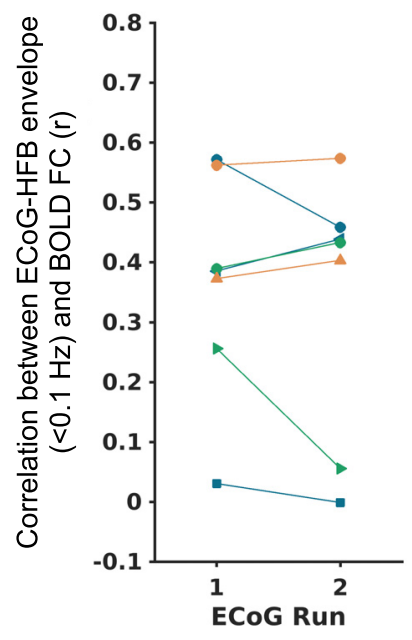

Figure 2. Within-subject spatial correlation between BOLD and ECOG-HFB functional connectivity when $A$ ) controlling for Euclidean distance between the seed region and each target region via partial correlation (and using $0.1-1 \mathrm{~Hz}$ HFB envelopes), $\boldsymbol{B}$ ) performing different preprocessing pipelines on the fMRI data (and using $0.1-1 \mathrm{~Hz} H F B$ envelopes), and $\boldsymbol{C}$ ) using $<0.1 \mathrm{~Hz} \mathrm{HFB}$ envelopes. Each subject is indicated with a different marker shape, and each network is labeled with a different color.

different times. We treated one ECoG run as discovery and the other as replication dataset.

In all three subjects with DMN coverage, we identified an electrode location in the mPFC that showed strong FC with the $\mathrm{PMC}$ relative to most other target electrode locations, in both BOLD and ECoG-HFB. In Figure $1 A$, a striking correspondence between the anatomical distributions of seed-based FC is shown, where we plot an overlay of the strength of ECoG-HFB FC (in circles indicating electrode locations) and unthresholded BOLD FC (on the cortical pial surface). In each DMN subject, there was a positive spatial correlation between the degree of pairwise BOLD with ECoG-HFB FC in both discovery and replication datasets ( $r$ value range: $0.38-0.61$; all $p$ values $<0.01$; Fig. $1 A, E$ ). Time courses of single-subject BOLD and ECoG-HFB signals from $\mathrm{MPFC}$ and PMC electrode locations are shown in Figure $1 B$. In this example, the $\mathrm{mPFC}$ and PMC show tightly correlated activity with one another in both modalities $(r=0.84$ in 6 min of BOLD data, $r=0.65$ in a 1 min example segment of ECoG-HFB data) despite the different time scales investigated and the fact that each measurement was conducted in a different setting (i.e., not simultaneously).

Similar findings were seen in the DAN and FPCN. Specifically, for each network, we observed anatomically-specific FC in both BOLD and ECoG-HFB between core nodes relative to other target locations. In both BOLD and ECoG-HFB, seed-based FC revealed strikingly selective coupling between FEF and SPL in the two DAN subjects (Fig. 1C) and between dlPFC and aIPL in the two FPCN subjects (Fig. 1D). As with the DMN, the seed-based FC spatial patterns across all target electrodes were correlated between BOLD and ECoG-HFB within each subject for DAN $(r$ value range: $0.28-0.49$; all $p$ values $<0.01$ ) and FCPN ( $r$ value range: $0.51-0.63$; all $p$ values $<0.01$ ) seeds. At the group level, across seed FC maps for all networks, the mean \pm SD spatial correlation between BOLD versus ECoG-HFB FC was $r=0.53 \pm$ 0.14 and $r=0.48 \pm 0.08$ for the discovery and replication ECoG datasets, respectively (Fig. $1 E$ ). To aid interpretation of the spatial correspondence between ECoG-HFB and fMRI FC across two independent ECoG runs, we also present an overlay of maps on the inflated cortical surface in Figure $1 F$. In this example patient (S3) within the DMN cohort, there was additional electrode coverage in the lateral parietal lobe. Reproducible and selective ECoG-HFB FC can be seen between the MPFC and lateral parietal cortex (spanning angular gyrus, a well described node within $\mathrm{DMN}$ ) in addition to the strong, persistent FC between mPFC and PMC.

The BOLD versus ECoG-HFB FC spatial correlations across seeds in all networks remained very similar when performing partial correlations controlling for Euclidean distance between electrode locations $(r$ mean $\pm \mathrm{SD}=0.53 \pm 0.14$ and $0.47 \pm 0.09$ for discovery and replication ECoG datasets, respectively; Fig. $2 A)$. The relationships also remained consistent regardless of whether fMRI data were preprocessed with the denoising strategies of global signal regression, "aCompCor," or "ICA-AROMA" (Fig. $2 B$ ). Notably, our main focus is on the ultraslow fluctuations (0.1-1 Hz) of HFB envelope signals, consistent with previous work (Keller et al., 2013; Foster et al., 2015) and optimizing the number of cycles of the signal investigated. However, we also repeated our analyses with the HFB envelope signals filtered to $<0.1$ $\mathrm{Hz}$ (more consistent with FC measures in $\mathrm{PMRI}$ ), and this largely resulted in positive spatial correlation between BOLD and ECoG FC, but the ECoG-fMRI relationship was weaker and more variable $(r$ mean $\pm \mathrm{SD}=0.37 \pm 0.19$ and $0.34 \pm 0.22$ for discovery and replication datasets, respectively; Fig. 2C).

We then interrogated whether within-network HFB envelope correlations were specific to zero-lag as opposed to lagged correlations. For each subject and network, we defined a within-network region pair as the seed electrode plus an electrode within the target node of interest for a given network (e.g., $\mathrm{mPFC}$ and PMC for the DMN) that had showed high ECoG-HFB FC with the seed (top 10 percentile among all target electrodes). Across all of these withinnetwork region pairs, cross-correlations of shifted time series revealed a mean peak at zero-lag $(0.0 \pm 0.03 \mathrm{~s}$; Fig. 3$)$. Thus, consistent with previous findings from a single within-network pair (Foster 
et al., 2015), across multiple networks, we did not find a clear systematic delay.

\section{ECoG FC during sleep}

Intrinsic BOLD FC is persistent across different consciousness states (Vincent et al., 2007; Larson-Prior et al., 2009). Therefore, we next tested whether the organized ECoG-HFB FC within networks (identified at rest) was also present in the sleep state. In a subject (S3) who had unique simultaneous coverage within all three networks of interest, we found that anatomical patterns of seed-based FC within the DMN, DAN, and FPCN appeared largely similar during sleep compared with wakeful rest (Fig. 4A). As can be seen in an example $60 \mathrm{~s}$ window in Figure $4 B$, ECoG-HFB envelope time courses showed strong interelectrode coupling during sleep for representative pairs of regions within each network. Overall, across all three networks, there were generally strong, positive spatial correlations of seed-based FC for wakeful rest (both runs) versus sleep ( $r$ value range: $0.77-0.92$; all $p$ values $<0.01$; Fig. $4 C$ ). Moreover, there were positive spatial correlations between sleep and BOLD FC for seeds within each network (DMN: $r=0.65$, DAN: $r=0.50$, FPCN: $r=0.59$; all $p$ values $<0.01$; Fig. $4 D$ ). These findings support the notion that electrophysiological FC between core nodes of the DMN, DAN, and FPCN is largely state-independent.

\section{Frequency dependence of ECoG FC}

Our results so far confirm that ECoG-HFB envelope FC corresponds to BOLD FC and is persistent across wakefulness and sleep states for key nodes of the DMN, DAN and FPCN. These findings are consistent with previous studies of other brain regions (Keller et al., 2013; Foster et al., 2015; Hacker et al., 2017), but some iEEG evidence also suggests that envelope signals from lower frequencies ranges may be associated with BOLD FC (Wang et al., 2012; Liu et al., 2015; Hacker et al., 2017). Thus, we next extended our analyses of ECoG envelope signals to frequencies of activity $<70 \mathrm{~Hz}$.

Figure 5 shows ECoG seed-based resting FC for delta (1-3 $\mathrm{Hz})$, theta $(4-7 \mathrm{~Hz}), \alpha(8-12 \mathrm{~Hz})$, low $\beta(13-29 \mathrm{~Hz})$, high $\beta$ $(30-39 \mathrm{~Hz})$, gamma $(40-70 \mathrm{~Hz})$, as well as HFB envelopes (all filtered at $0.1-1 \mathrm{~Hz}$ ). Focusing on within-network electrodes (arrows), as previously defined based on HFB envelope FC, it can be seen qualitatively that seed-target FC is sometimes clearly present in the DMN, DAN, and FPCN across multiple frequencies. However, for frequencies lower than HFB, within-network FC was typically more variable across subjects and often less anatomically specific.

To further characterize how within-network ECoG FC varies across frequency ranges, we plotted the activity correlations between within-network region pairs as a function of frequency (Fig. 6A). A repeated-measures ANOVA revealed a significant interaction between frequency and within-network FC strength $(p=0.007)$. As can be seen, FC is most consistent across subjects and is strongest for HFB compared with all other frequency ranges. However, on average, FC was also high in the delta and theta ranges. The group average trend suggested that FC tended to be stronger for low (delta, theta) and high (gamma, HFB) frequencies but weaker for mid-range frequencies $(\alpha, \beta)$. The trough of within-network FC in the $\beta$ range is consistent with previous work (Hacker et al., 2017).

To assess the anatomical similarity of FC patterns across frequencies, we performed interfrequency FC spatial correlations for all pairs of frequency ranges for seed-based FC to all target electrodes (average similarity matrix across subjects and networks shown in Fig. 6B). The general trend was that closely spaced frequency ranges showed more similarity with one another; however, HFB FC was more strongly associated with theta compared with $\alpha$ and $\beta$ FC. Interestingly, all frequency ranges showed positive spatial correlations with resting-state BOLD FC within subjects (Fig. 6C), but there was an interaction between frequency and strength of BOLD-ECoG FC correspondence $(p=0.015)$. Across all frequencies, the strength of within-network ECoG FC (between predefined region pairs) was positively correlated with the strength of BOLD-ECoG spatial correlation $(r=0.53$, $\left.p=9.6 \times 10^{-5}\right)$.

\section{Dynamic FC}

Our approach so far has revealed evidence for stable and reproducible ECoG FC within networks. Given that such organized FC was present (to some degree) for different frequency ranges, an important remaining question concerns whether the dynamics of FC in these distinct frequency ranges carry redundant information or show temporal divergence. The presence of cross-frequency temporal divergence of FC between a single pair of within-network regions could imply that multiple, distinct neurophysiological sources underlie FC.

In an attempt to characterize such cross-frequency dynamics between within-network region pairs, we adopted a dynamic FC analysis approach (Chang and Glover, 2010; Hutchison et al., 2013; Calhoun et al., 2014). We performed interelectrode slidingwindow correlations on envelope signals during the resting state using $5 \mathrm{~s}$ step size across $10 \mathrm{~s}$ windows of resting-state data. Importantly, the temporal resolution of fMRI precludes interrogation of connectivity at this time scale (Leonardi and Van De Ville, 2015). At this time-resolved scale, for HFB and other bands of ECoG signals, FC within all networks fluctuated considerably and included windows with both positive and negative correlations. However, windows of strong, positive correlations were commonly present, as expected based on the static FC results. In Figure $7 A$, we show examples of time-varying correlated activity in the HFB and $\alpha$ ranges (envelopes filtered between $0.1-1 \mathrm{~Hz}$ ). As can be seen, temporal fluctuations in $\mathrm{FC}$ within different frequency ranges between the same pair of regions often diverge from one another. Extending these analyses to all frequency ranges, we found that interfrequency 
A

S3

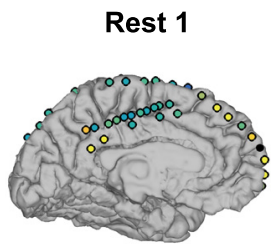

DAN

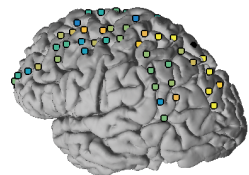

FPCN

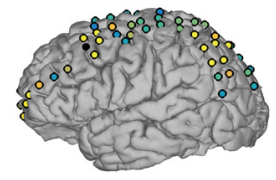

$-0.1 \quad$ ECoG-HFB ( $r) \quad 0.4$

Rest 2
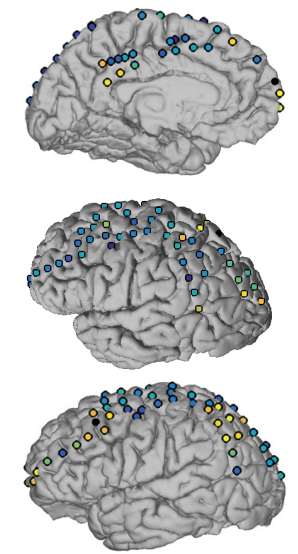

- Seed
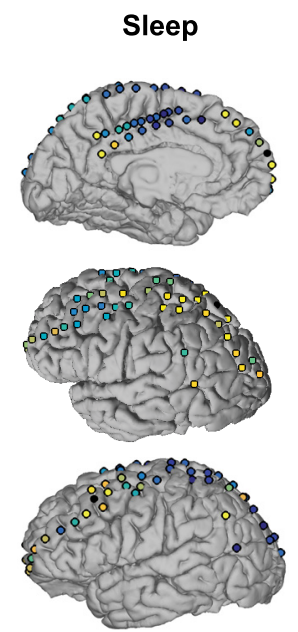

Sleep (ECoG) versus Rest (BOLD)
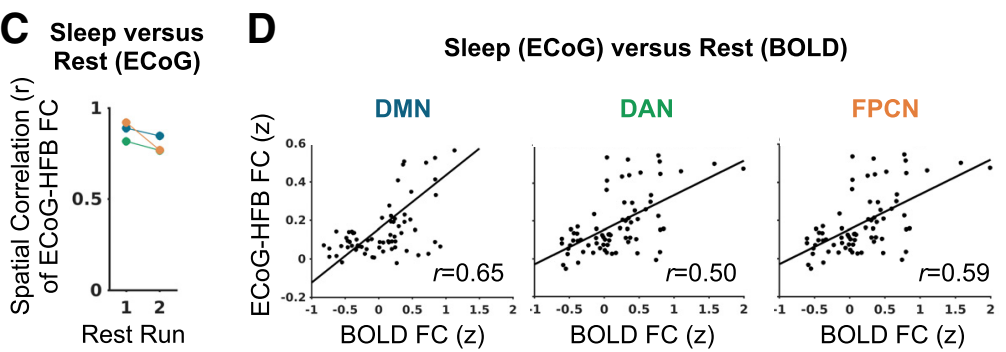

B
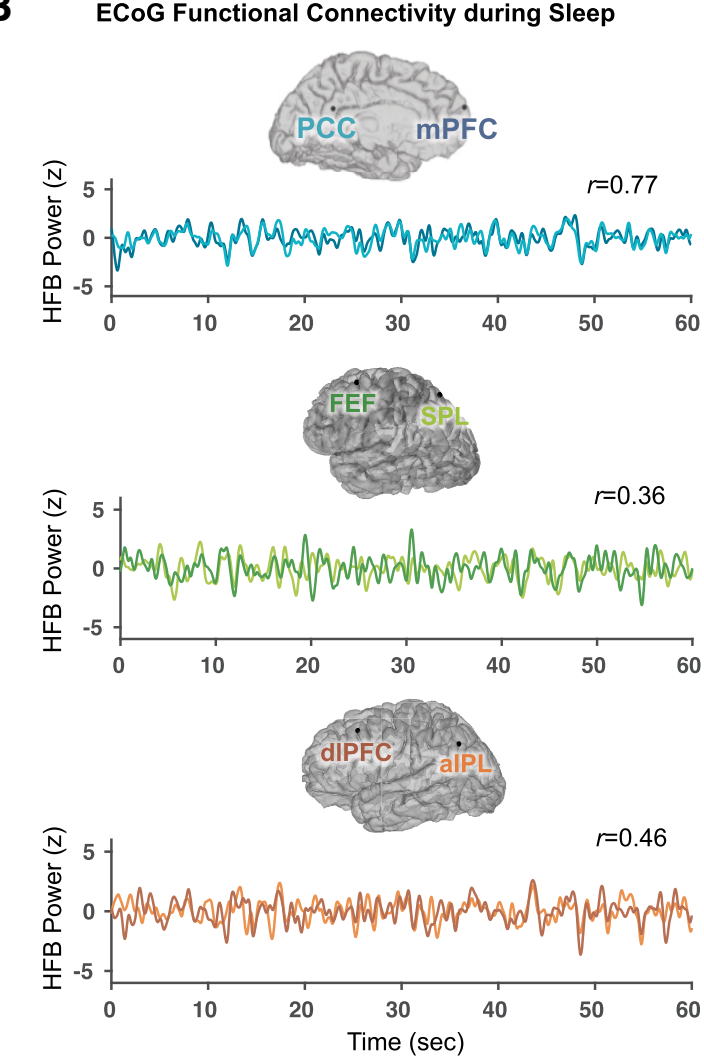

Figure 4. Persistence of ECOG-HFB envelope functional connectivity within networks during sleep and wakeful rest in a single subject(S3). A) On the cortical surface projections, the seed electrode location is shown as a black dot. Other electrode locations are shown as circles filled with a color representing the degree of ECoG-HFB envelope correlation with the seed (unanalyzed electrodes not shown). B) Example correlated time series of the ECOG-HFB envelope during sleep for nodes within the DMN, DAN and FPCN. C) Spatial correlations between functional connectivity during sleep versus each of the two resting state runs for seed locations in the DMN, DAN and FPCN. D) Spatial correlations between ECoG-HFB envelope and BOLD functional connectivity within the subject.

FC temporal correlations were highly variable across subjects and networks (Fig. $7 B$ ), suggesting that multiple distinct frequencies follow different temporal profiles of fluctuations, which clearly argues against a universal source of dynamic changes of FC between a given pair of nodes.

\section{Discussion}

Our work offers novelty beyond past studies in several key ways: (1) we investigated a unique cohort of patients with iEEG coverage within previously unstudied key regions of intrinsic networks; (2) we systematically show that electrophysiological intrinsic networks are generalizable across individuals, anatomical regions, and behavioral states; and (3) we show that different frequencies of electrophysiological FC have different temporal profiles. Together, the electrophysiological intrinsic FC that we report here is a generalizable phenomenon across individuals, brain networks, and behavioral states.

High-frequency broadband power and BOLD connectivity

High-frequency broadband power near an electrode serves as a reliable index of local population spiking (Nir et al., 2007; Manning et al., 2009). High gamma/HFB power is also a positive correlate of evoked BOLD activation in individual brain areas (Logothetis et al., 2001; Mukamel et al., 2005; Lachaux et al., 2007; Mantini et al., 2007; Nir et al., 2007; Shmuel and Leopold, 2008). Additionally, local spontaneous BOLD fluctuations have been associated with high gamma/HFB power (but also other frequencies of activity; Laufs et al., 2003; Mantini et al., 2007;
Schölvinck et al., 2010; Hutchison et al., 2015; but see Winder et al., 2017).

Previous human and nonhuman primate studies of intracranial recordings that focused specifically on spontaneous FC have provided evidence for selective coupling within sensory/motor networks (Leopold et al., 2003; He et al., 2008; Nir et al., 2008; Fukushima et al., 2012) as well as within association cortices (Keller et al., 2013; Ko et al., 2013; Foster et al., 2015; Liu et al., 2015; Hacker et al., 2017). All of these studies reported on anatomically selective FC of HFB (or a comparable range) envelope signals. Given the close correspondence of such spatial patterns with those found in $\mathrm{PMRI}$, these findings collectively suggest that intrinsic BOLD FC throughout human brain may be driven by coordinated local activity (e.g., spiking events) in spatially segregated regions. Indeed, a causal relationship between signal envelope correlations (mainly in the gamma/HFB range) and BOLD FC was recently reported in mouse cortex using optogenetic entrainment (Mateo et al., 2017).

Our results suggest that for a limited number of well defined within-network region pairs, HFB envelope signals during wakeful rest show peak correlations at a mean lag that is near zero, in line with previous work (Foster et al., 2015). Using rs-fMRI, Mitra et al. $(2014,2015)$ demonstrated temporal delays ("lag threads") of FC between specific region pairs within and between networks. However, some pairs did not show a clear delay, and it is possible that those anatomically correspond to the specific electrode pairs investigated here. Alternatively, there could be 


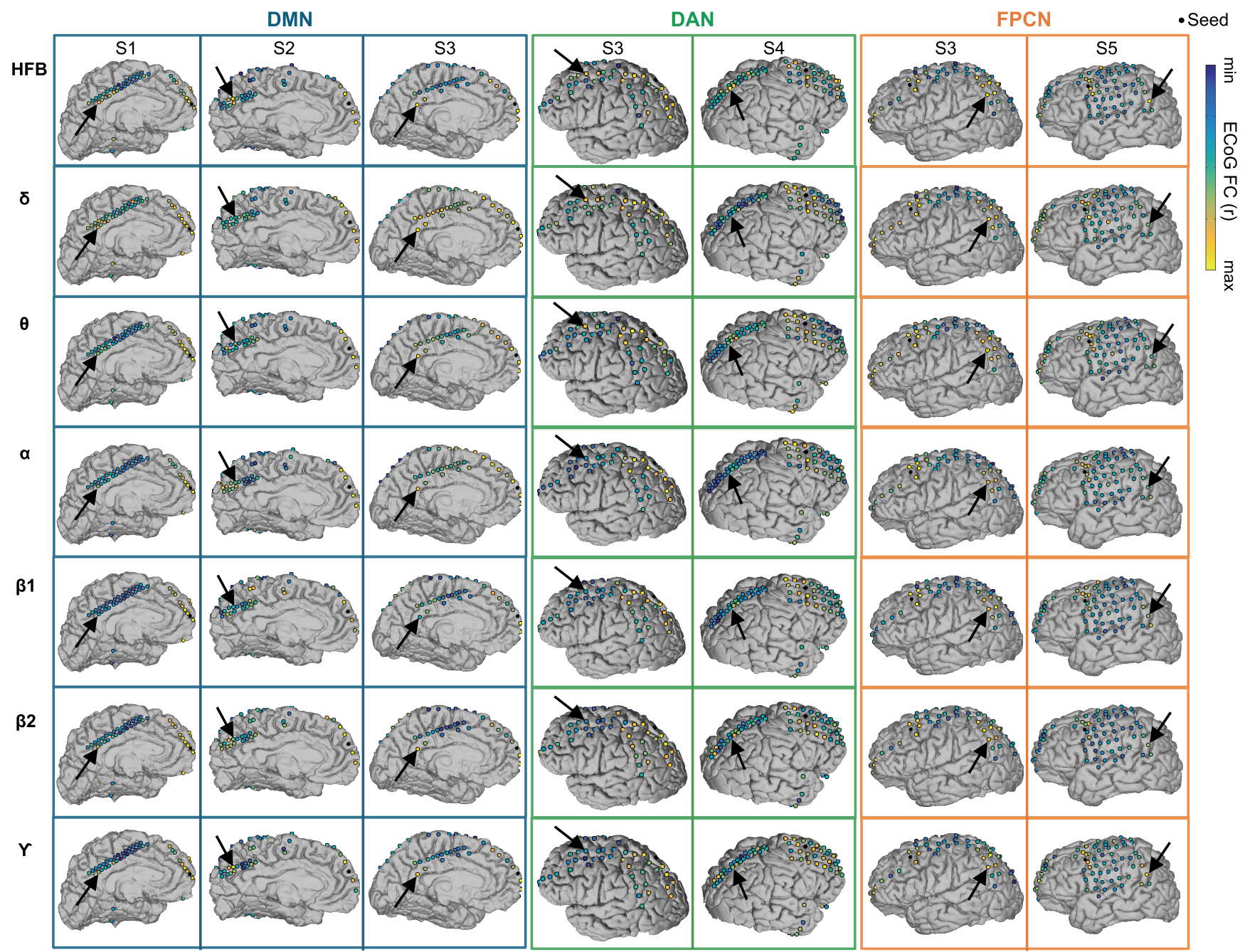

Figure 5. Resting state ECOG functional connectivity across multiple frequencies. For each subject (S1-S5) and network, a seed electrode location is shown as a black dot. Other electrode locations are shown as circles filled with a color representing the degree of $\mathrm{EC} O \mathrm{G}$ envelope correlation with the seed (from one representative $\mathrm{EC} O \mathrm{G}$ run) for the frequency ranges of $\mathrm{HFB}(70-170 \mathrm{~Hz}), \delta(1-3$ $\mathrm{Hz}), \theta(4-7 \mathrm{~Hz}), \alpha(8-12 \mathrm{~Hz}), \beta 1(13-29 \mathrm{~Hz}), \beta 2(30-39 \mathrm{~Hz})$, and $\gamma(40-70 \mathrm{~Hz})$ (unanalyzed electrodes not shown). The color scale is anchored at minimum and maximum r values, disregarding electrodes immediately neighboring the seed. Arrows indicate a distant target electrode within the network that showed an HFB envelope correlation with the seed that was in the top 10 percentile of all target electrodes.

differences in the source of interregional activity delays in hemodynamic compared with electrophysiological measurements. Some evidence indicates that there is correspondence between ECoG and BOLD lags for hippocampal-cortical FC (Mitra et al., 2016). Future work is needed to systematically assess the potential electrophysiological basis of FC lags within and between a wider range of networks.

\section{Frequency dependence of FC}

Although our findings of anatomically selective HFB envelope FC and its association with BOLD was consistent across subjects and networks, we found that envelope FC for lower frequencies was sometimes present. This finding is generally in line with those in previous human iEEG studies that included analyses of lowerfrequency ranges (Nir et al., 2008; Foster et al., 2015). In contrast, Hacker et al. (2017) suggested that lateral cortical regions in the DMN and FPCN show FC of the theta signal envelope that correlates with BOLD FC within subjects, whereas other networks including DAN showed such a relationship for $\alpha$ but not theta. Notably, however, such BOLD-iEEG FC correlations for lower frequencies were still weaker than those found for the HFB range (Hacker et al., 2017).

We also found evidence for BOLD-iEEG FC correlations within subjects for multiple frequency ranges, but close inspection of anatomical specificity indicated that within-network coupling was most consistent in the HFB range. Due to a limited sample size and a focus on cross-subject anatomically-matched region pairs within networks, we did not formally compare potential FC frequency differences among networks. Thus, our study did not address the hypothesis of carrier frequency spectral specificity for distinct networks, as advanced by Hacker et al. (2017), and our findings do not necessarily contradict the possibility of cross-network frequency-specific FC signatures.

Recently, human MEG studies have revealed similarities within individuals between BOLD- and frequency-specific (mainly $\alpha / \beta$ envelope) FC spatial patterns, with some heterogeneity across networks in the frequency that best correlates with BOLD FC (Brookes et al., 2011; Hipp and Siegel, 2015). Although higher frequencies can be difficult to study in MEG, Hipp and Siegel 

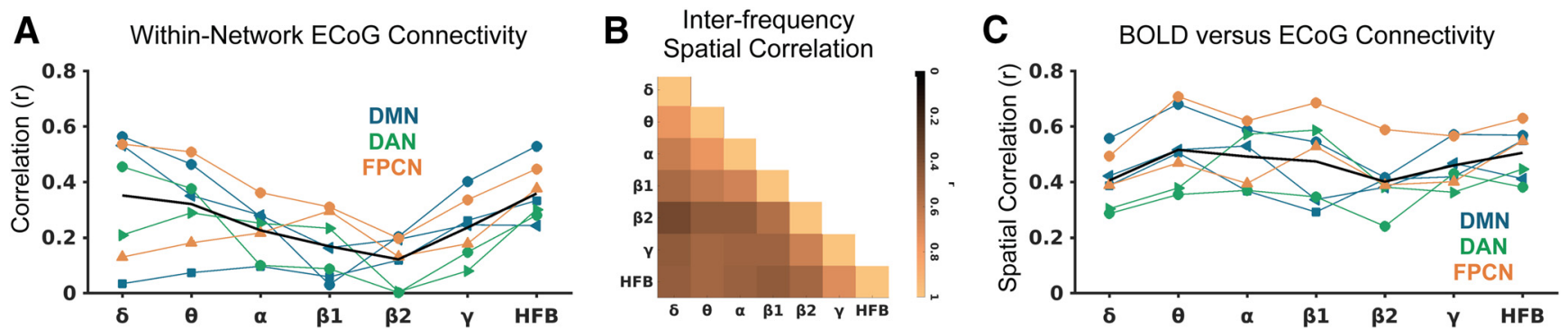

Figure 6. Spatial properties of resting state $\mathrm{ECOG}$ functional connectivity for different frequency ranges. $\boldsymbol{A}) \mathrm{EC}(\mathrm{G}$ envelope (0.1-1 Hz) correlation between within-network region pairs as a function of frequency range (average between two resting state $E(0 G$ runs). $B$ ) Spatial correlation matrix of all pairs of frequency ranges for seed-based functional connectivity to all target electrodes (average across all subjects and networks). $C$ ) Resting state $\mathrm{fMRI}$ versus $\mathrm{EC} O \mathrm{G}$ envelope functional connectivity as a function of $\mathrm{EC} 0 \mathrm{G}$ frequency range (average between two resting state $\mathrm{EC} 0 \mathrm{G}$ runs).

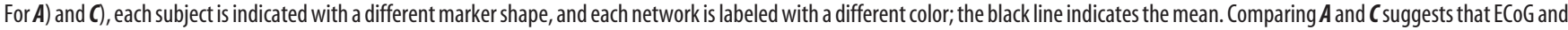
fMRI FC measures are correlated regardless of the chosen carrier frequency of electrophysiological activity, but FC measures are higher and more consistent across networks using HFB as the carrier frequency of choice.
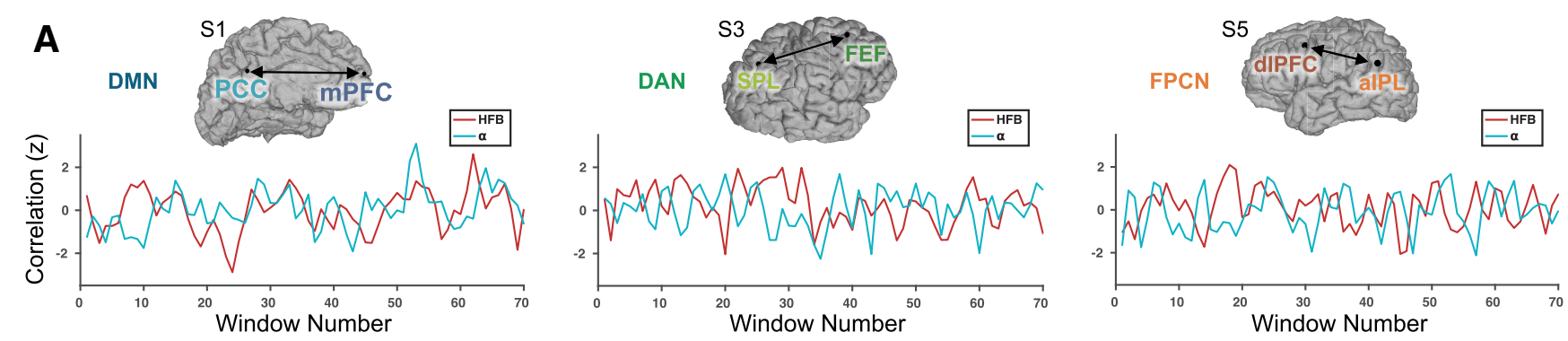

B Inter-frequency FC Temporal Correlation (All Frequencies) $\begin{array}{rrrrrrrrrrr}-1 & -0.8 & -0.6 & -0.4 & -0.2 & 0 & 0.2 & 0.4 & 0.6 & 0.8 & 1\end{array}$
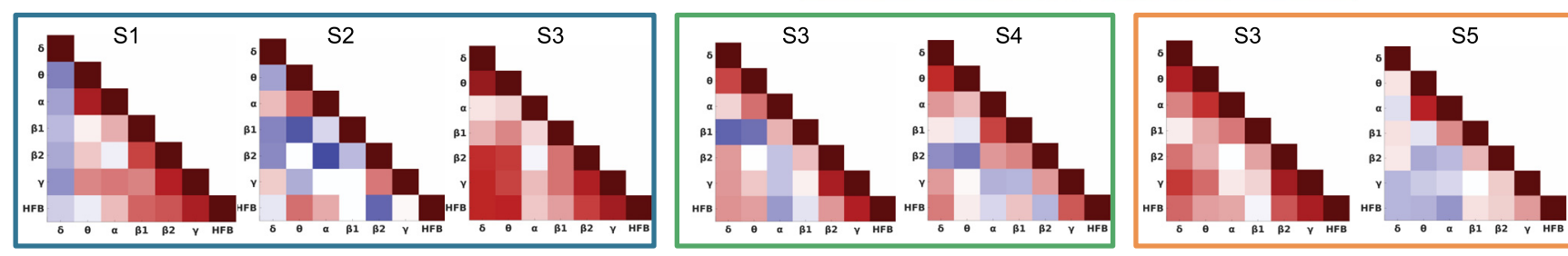

Figure 7. Dynamic ECOG functional connectivity within intrinsic networks. $A$ ) Sliding-window correlations between activity measured during wakeful rest at electrodes in the default mode network (DMN), dorsal attention network (DAN) and frontoparietal control network (FPCN) in three example subjects, respectively. For HFB and alpha envelope signals (0.1-1 Hz filtered), the correlation (Fisher r-to-z transformed) between electrodes is plotted in 10-second windows (5 second step size between adjacent windows). $\boldsymbol{B}$ ) Inter-frequency correlations of dynamic functional connectivity. Between all pairs of frequencies, correlations between 10-second sliding window functional connectivity estimates (with 5 -second step size) are shown. Results are shown for all subjects for within-network region pairs in the default mode (left, blue box), dorsal attention (middle, green box), and frontoparietal control (right, orange box) networks. Frequencies shown include $\delta(1-3 \mathrm{~Hz}), \theta(4-7 \mathrm{~Hz}), \alpha(8-12 \mathrm{~Hz}), \beta 1(13-29 \mathrm{~Hz}), \beta 2(30-39 \mathrm{~Hz}), \gamma(40-70 \mathrm{~Hz})$ and HFB $(70-170 \mathrm{~Hz})$. alPL = anterior inferior parietal lobule; dlPFC = dorsolateral prefrontal cortex; FEF = frontal eye fields; $\mathrm{mPFC}=$ medial prefrontal cortex; $\mathrm{PCC}=$ posterior cingulate cortex; $\mathrm{SPL}=$ superior parietal lobule.

(2015) showed that after accounting for interfrequency differences in signal-to-noise, envelope signals of frequencies up to 128 $\mathrm{Hz}$ contained FC patterns that were spatially similar to those found in BOLD. Those findings are consistent with our results and with other iEEG studies. Moreover, our findings of spatial correlation between BOLD and iEEG FC for multiple lowfrequency ranges are also in line with those results. Intracranial recordings in monkeys also suggest that intrinsic FC can be described as a broadband phenomenon (Liu et al., 2015). However, we emphasize here that a focus on HFB envelope signals revealed anatomically selective coupling between nodes of well described human BOLD networks.

A possible explanation for the finding that within-network FC is found for both low and high frequencies is interaction between these frequencies. Wang et al. (2012) proposed that BOLD FC is shaped by coordinated events occurring between low $(<20 \mathrm{~Hz})$ and high $(>40 \mathrm{~Hz})$ frequencies (i.e., cross-frequency coupling). A recent study in rat striatum also suggested that BOLD FC is associated with coupling between the phase of delta oscillations and the amplitude of high-frequency activity (Jaime et al., 2017). Under this framework, low frequencies may coordinate excitability between distant brain regions, whereas high frequencies reflect local computations (Buzsáki and Wang, 2012; Jensen et al., 2014). Importantly, the dominant frequencies involved in crossfrequency coupling could vary across the brain and among behavioral states; for instance, the PMC within the DMN shows local theta-HFB coupling at rest (Foster and Parvizi, 2012), whereas visual cortical regions show $\alpha-\mathrm{HFB}$ coupling at rest (Foster and Parvizi, 2012), which may be modulated by visual task performance (Voytek et al., 2010). Our findings are broadly compatible with the possibility that BOLD FC is shaped by crossfrequency coupling.

\section{Dynamic FC}

The study of dynamic FC, which has recently gained widespread attention, is dominated largely by fMRI studies (Hutchison et al., 
2013; Calhoun et al., 2014). There remains debate over the significance of dynamic FC. On the one hand, dynamic FC could represent a systematic exploration of possible network configurations (Deco et al., 2013), changes in arousal (Tagliazucchi and Laufs, 2014), and/or ongoing cognitive processes (Kucyi et al., 2018). On the other hand, some investigators have questioned whether dynamic BOLD FC is of predominantly non-neural origin, reflecting sampling variability and measurement noise (Handwerker et al., 2012; Keilholz et al., 2013; Laumann et al., 2017; Liégeois et al., 2017).

Here we present preliminary evidence for spontaneous ECoG FC fluctuations across short time windows (10 s). Although the signal-to-noise ratio of ECoG greatly exceeds that of fMRI, and concerns about spurious FC fluctuations are dampened, it is still possible that sampling variability was a factor. There remains no consensus on how to best test for the presence of genuine FC fluctuations, especially when no simultaneous and independent neural or behavioral measure is available (Liégeois et al., 2017; Kucyi et al., 2018). We found that FC showed divergence, or unique temporal profiles, among distinct frequency bands. These findings are in line with a previous study with simultaneous fMRI with intracranial recordings in right and left somatosensory cortex in rats, showing that interhemispheric BOLD FC fluctuations are correlated with signal envelope FC distinctly for different frequency ranges (Thompson et al., 2013). Collectively, these findings argue that there may be no single common source of variations in FC. Although the vast majority of studies in the field consider dynamic FC based on a single metric (BOLD signal) at each brain region, our findings additionally highlight that withinnetwork dynamic FC may be a non-unitary phenomenon, shaped by multiple, dissociable neurophysiological processes that are represented in distinct frequencies of activity.

\section{Conclusion}

Here we provide evidence for a neural correlate of intrinsic BOLD FC that is generalizable across the most widely investigated human brain networks.

Our findings reinforce that the phenomenon of intrinsic FC is a fundamental property of the human brain, rather than an idiosyncratic feature in fMRI measurements. At the same time, our findings on unique temporal profiles of distinct electrophysiological frequencies indicate that fMRI presents an oversimplified view of intrinsic networks. Although we have begun to explore how FC spontaneously fluctuates over time and in different frequency ranges, future studies that include behavioral measures are needed to shed light on the possible distinct roles of FC at different frequencies in ongoing cognition.

\section{References}

Andrews-Hanna JR, Reidler JS, Sepulcre J, Poulin R, Buckner RL (2010) Functional-anatomic fractionation of the brain's default network. Neuron 65:550-562. CrossRef Medline

Behzadi Y, Restom K, Liau J, Liu TT (2007) A component based noise correction method (CompCor) for BOLD and perfusion based fMRI. Neuroimage 37:90-101. CrossRef Medline

Birn RM, Murphy K, Bandettini PA (2008) The effect of respiration variations on independent component analysis results of resting state functional connectivity. Hum Brain Mapp 29:740-750. CrossRef Medline

Biswal B, Yetkin FZ, Haughton VM, Hyde JS (1995) Functional connectivity in the motor cortex of resting human brain using echo-planar MRI. Magn Reson Med 34:537-541. CrossRef Medline

Braga RM, Buckner RL (2017) Parallel interdigitated distributed networks within the individual estimated by intrinsic functional connectivity. Neuron 95:457-471. e5. CrossRef Medline

Brookes MJ, Woolrich M, Luckhoo H, Price D, Hale JR, Stephenson MC,
Barnes GR, Smith SM, Morris PG (2011) Investigating the electrophysiological basis of resting state networks using magnetoencephalography. Proc Natl Acad Sci U S A 108:16783-16788. CrossRef Medline

Buckner RL, Krienen FM, Yeo BT (2013) Opportunities and limitations of intrinsic functional connectivity MRI. Nat Neurosci 16:832-837. CrossRef Medline

Buzsáki G, Wang XJ (2012) Mechanisms of gamma oscillations. Annu Rev Neurosci 35:203-225. CrossRef Medline

Calhoun VD, Miller R, Pearlson G, Adalı T (2014) The chronnectome: time-varying connectivity networks as the next frontier in fMRI data discovery. Neuron 84:262-274. CrossRef Medline

Chai XJ, Castañón AN, Ongür D, Whitfield-Gabrieli S (2012) Anticorrelations in resting state networks without global signal regression. Neuroimage 59:1420-1428. CrossRef Medline

Chang C, Glover GH (2009) Relationship between respiration, end-tidal CO2, and BOLD signals in resting-state fMRI. Neuroimage 47:13811393. CrossRef Medline

Chang C, Glover GH (2010) Time-frequency dynamics of resting-state brain connectivity measured with fMRI. Neuroimage 50:81-98. CrossRef Medline

Ciric R, Wolf DH, Power JD, Roalf DR, Baum GL, Ruparel K, Shinohara RT, Elliott MA, Eickhoff SB, Davatzikos C, Gur RC, Gur RE, Bassett DS, Satterthwaite TD (2017) Benchmarking of participant-level confound regression strategies for the control of motion artifact in studies of functional connectivity. Neuroimage 154:174-187. CrossRef Medline

Cole MW, Bassett DS, Power JD, Braver TS, Petersen SE (2014) Intrinsic and task-evoked network architectures of the human brain. Neuron 83 : 238-251. CrossRef Medline

Corbetta M, Shulman GL (2002) Control of goal-directed and stimulusdriven attention in the brain. Nat Rev Neurosci 3:201-215. CrossRef Medline

Deco G, Jirsa VK, McIntosh AR (2013) Resting brains never rest: computational insights into potential cognitive architectures. Trends Neurosci 36:268-274. CrossRef Medline

de Pasquale F, Della Penna S, Snyder AZ, Lewis C, Mantini D, Marzetti L, Belardinelli P, Ciancetta L, Pizzella V, Romani GL, Corbetta M (2010) Temporal dynamics of spontaneous MEG activity in brain networks. Proc Natl Acad Sci U S A 107:6040-6045. CrossRef Medline

de Pasquale F, Della Penna S, Snyder AZ, Marzetti L, Pizzella V, Romani GL, Corbetta M (2012) A cortical core for dynamic integration of functional networks in the resting human brain. Neuron 74:753-764. CrossRef Medline

Dykstra AR, Chan AM, Quinn BT, Zepeda R, Keller CJ, Cormier J, Madsen JR, Eskandar EN, Cash SS (2012) Individualized localization and cortical surface-based registration of intracranial electrodes. Neuroimage 59: 3563-3570. CrossRef Medline

Engel AK, Gerloff C, Hilgetag CC, Nolte G (2013) Intrinsic coupling modes: multiscale interactions in ongoing brain activity. Neuron 80:867-886. CrossRef Medline

Fischl B, Sereno MI, Dale AM (1999) Cortical surface-based analysis. II: inflation, flattening, and a surface-based coordinate system. Neuroimage 9:195-207. CrossRef Medline

Foster BL, Parvizi J (2012) Resting oscillations and cross-frequency coupling in the human posteromedial cortex. Neuroimage 60:384-391. CrossRef Medline

Foster BL, Rangarajan V, Shirer WR, Parvizi J (2015) Intrinsic and taskdependent coupling of neuronal population activity in human parietal cortex. Neuron 86:578-590. CrossRef Medline

Foster BL, He BJ, Honey CJ, Jerbi K, Maier A, Saalmann YB (2016) Spontaneous neural dynamics and multi-scale network organization. Front Syst Neurosci 10:7. CrossRef Medline

Fox MD, Raichle ME (2007) Spontaneous fluctuations in brain activity observed with functional magnetic resonance imaging. Nat Rev Neurosci 8:700-711. CrossRef Medline

Fox MD, Corbetta M, Snyder AZ, Vincent JL, Raichle ME (2006) Spontaneous neuronal activity distinguishes human dorsal and ventral attention systems. Proc Natl Acad Sci U S A 103:10046-10051. CrossRef Medline

Fukushima M, Saunders RC, Leopold DA, Mishkin M, Averbeck BB (2012) Spontaneous high-gamma band activity reflects functional organization of auditory cortex in the awake macaque. Neuron 74:899-910. CrossRef Medline

Greicius MD, Krasnow B, Reiss AL, Menon V (2003) Functional connectiv- 
ity in the resting brain: a network analysis of the default mode hypothesis. Proc Natl Acad Sci U S A 100:253-258. CrossRef Medline

Groppe DM, Bickel S, Dykstra AR, Wang X, Mégevand P, Mercier MR, Lado FA, Mehta AD, Honey CJ (2017) iELVis: an open source MATLAB toolbox for localizing and visualizing human intracranial electrode data. J Neurosci Methods 281:40-48. CrossRef Medline

Hacker CD, Snyder AZ, Pahwa M, Corbetta M, Leuthardt EC (2017) Frequency-specific electrophysiologic correlates of resting state fMRI networks. Neuroimage 149:446-457. CrossRef Medline

Handwerker DA, Roopchansingh V, Gonzalez-Castillo J, Bandettini PA (2012) Periodic changes in fMRI connectivity. Neuroimage 63:17121719. CrossRef Medline

He BJ, Snyder AZ, Zempel JM, Smyth MD, Raichle ME (2008) Electrophysiological correlates of the brain's intrinsic large-scale functional architecture. Proc Natl Acad Sci U S A 105:16039-16044. CrossRef Medline

Hipp JF, Siegel M (2015) BOLD fMRI correlation reflects frequency-specific neuronal correlation. Curr Biol 25:1368-1374. CrossRef Medline

Honey CJ, Sporns O, Cammoun L, Gigandet X, Thiran JP, Meuli R, Hagmann P (2009) Predicting human resting-state functional connectivity from structural connectivity. Proc Natl Acad Sci U S A 106:2035-2040. CrossRef Medline

Hutchison RM, Womelsdorf T, Allen EA, Bandettini PA, Calhoun VD, Corbetta M, Della Penna S, Duyn JH, Glover GH, Gonzalez-Castillo J, Handwerker DA, Keilholz S, Kiviniemi V, Leopold DA, de Pasquale F, Sporns O, Walter M, Chang C (2013) Dynamic functional connectivity: promise, issues, and interpretations. Neuroimage 80:360-378. CrossRef Medline

Hutchison RM, Hashemi N, Gati JS, Menon RS, Everling S (2015) Electrophysiological signatures of spontaneous BOLD fluctuations in macaque prefrontal cortex. Neuroimage 113:257-267. CrossRef Medline

Jaime S, Gu H, Sadacca BF, Stein EA, Cavazos JE, Yang Y, Lu H (2017) Delta rhythm orchestrates the neural activity underlying the resting state BOLD signal via phase-amplitude coupling. Cereb Cortex. Advance online publication. doi: 10.1093/cercor/bhx310. Medline

Jenkinson M, Beckmann CF, Behrens TE, Woolrich MW, Smith SM (2012) Fsl. Neuroimage 62:782-790. CrossRef Medline

Jensen O, Gips B, Bergmann TO, Bonnefond M (2014) Temporal coding organized by coupled alpha and gamma oscillations prioritize visual processing. Trends Neurosci 37:357-369. CrossRef Medline

Keilholz SD, Magnuson ME, Pan WJ, Willis M, Thompson GJ (2013) Dynamic properties of functional connectivity in the rodent. Brain Connect 3:31-40. CrossRef Medline

Keller CJ, Bickel S, Honey CJ, Groppe DM, Entz L, Craddock RC, Lado FA, Kelly C, Milham M, Mehta AD (2013) Neurophysiological investigation of spontaneous correlated and anticorrelated fluctuations of the BOLD signal. J Neurosci 33:6333-6342. CrossRef Medline

Kiebel SJ, Friston KJ (2004) Statistical parametric mapping for event-related potentials: I. generic considerations. Neuroimage 22:492-502. CrossRef Medline

Ko AL, Weaver KE, Hakimian S, Ojemann JG (2013) Identifying functional networks using endogenous connectivity in gamma band electrocorticography. Brain Connect 3:491-502. CrossRef Medline

Kucyi A, Tambini A, Sadaghiani S, Keilholz S, Cohen JR (2018) Spontaneous cognitive processes and the behavioral validation of time-varying brain connectivity. Netw Neurosci, in press.

Lachaux JP, Fonlupt P, Kahane P, Minotti L, Hoffmann D, Bertrand O, Baciu M (2007) Relationship between task-related gamma oscillations and BOLD signal: new insights from combined fMRI and intracranial EEG. Hum Brain Mapp 28:1368-1375. CrossRef Medline

Larson-Prior LJ, Zempel JM, Nolan TS, Prior FW, Snyder AZ, Raichle ME (2009) Cortical network functional connectivity in the descent to sleep. Proc Natl Acad Sci U S A 106:4489-4494. CrossRef Medline

Laufs H, Krakow K, Sterzer P, Eger E, Beyerle A, Salek-Haddadi A, Kleinschmidt A (2003) Electroencephalographic signatures of attentional and cognitive default modes in spontaneous brain activity fluctuations at rest. Proc Natl Acad Sci U S A 100:11053-11058. CrossRef Medline

Laumann TO, Snyder AZ, Mitra A, Gordon EM, Gratton C, Adeyemo B, Gilmore AW, Nelson SM, Berg JJ, Greene DJ, McCarthy JE, Tagliazucchi E, Laufs H, Schlaggar BL, Dosenbach NUF, Petersen SE (2017) On the stability of BOLD fMRI correlations. Cereb Cortex 27:4719-4732. CrossRef Medline

Leonardi N, Van De Ville D (2015) On spurious and real fluctuations of dynamic functional connectivity during rest. Neuroimage 104:430-436. CrossRef Medline

Leopold DA, Murayama Y, Logothetis NK (2003) Very slow activity fluctuations in monkey visual cortex: implications for functional brain imaging. Cereb Cortex 13:422-433. CrossRef Medline

Liégeois R, Laumann TO, Snyder AZ, Zhou J, Yeo BTT (2017) Interpreting temporal fluctuations in resting-state functional connectivity MRI. Neuroimage 163:437-455. CrossRef Medline

Liu J, Newsome WT (2006) Local field potential in cortical area MT: stimulus tuning and behavioral correlations. J Neurosci 26:7779-7790. CrossRef Medline

Liu X, Yanagawa T, Leopold DA, Fujii N, Duyn JH (2015) Robust longrange coordination of spontaneous neural activity in waking, sleep and anesthesia. Cereb Cortex 25:2929-2938. CrossRef Medline

Logothetis NK, Pauls J, Augath M, Trinath T, Oeltermann A (2001) Neurophysiological investigation of the basis of the fMRI signal. Nature 412: 150-157. CrossRef Medline

Lu J, Liu H, Zhang M, Wang D, Cao Y, Ma Q, Rong D, Wang X, Buckner RL, Li K (2011) Focal pontine lesions provide evidence that intrinsic functional connectivity reflects polysynaptic anatomical pathways. J Neurosci 31:15065-15071. CrossRef Medline

Manning JR, Jacobs J, Fried I, Kahana MJ (2009) Broadband shifts in local field potential power spectra are correlated with single-neuron spiking in humans. J Neurosci 29:13613-13620. CrossRef Medline

Mantini D, Perrucci MG, Del Gratta C, Romani GL, Corbetta M (2007) Electrophysiological signatures of resting state networks in the human brain. Proc Natl Acad Sci U S A 104:13170-13175. CrossRef Medline

Mateo C, Knutsen PM, Tsai PS, Shih AY, Kleinfeld D (2017) Entrainment of arteriole vasomotor fluctuations by neural activity is a basis of bloodoxygenation-level-dependent "resting-state" connectivity. Neuron 96: 936-948.e3. CrossRef Medline

Mennes M, Kelly C, Zuo XN, Di Martino A, Biswal BB, Castellanos FX, Milham MP (2010) Inter-individual differences in resting-state functional connectivity predict task-induced BOLD activity. Neuroimage 50: 1690-1701. CrossRef Medline

Mitra A, Snyder AZ, Hacker CD, Raichle ME (2014) Lag structure in resting-state fMRI. J Neurophysiol 111:2374-2391. CrossRef Medline

Mitra A, Snyder AZ, Tagliazucchi E, Laufs H, Raichle ME (2015) Propagated infra-slow intrinsic brain activity reorganizes across wake and slowwave sleep. eLife 4:e10781. CrossRef Medline

Mitra A, Snyder AZ, Hacker CD, Pahwa M, Tagliazucchi E, Laufs H, Leuthardt EC, Raichle ME (2016) Human cortical-hippocampal dialogue in wake and slow-wave sleep. Proc Natl Acad Sci U S A 113:E6868E6876. CrossRef Medline

Mukamel R, Gelbard H, Arieli A, Hasson U, Fried I, Malach R (2005) Coupling between neuronal firing, field potentials, and FMRI in human auditory cortex. Science 309:951-954. CrossRef Medline

Nir Y, Fisch L, Mukamel R, Gelbard-Sagiv H, Arieli A, Fried I, Malach R (2007) Coupling between neuronal firing rate, gamma LFP, and BOLD fMRI is related to interneuronal correlations. Curr Biol 17:1275-1285. CrossRef Medline

Nir Y, Mukamel R, Dinstein I, Privman E, Harel M, Fisch L, Gelbard-Sagiv H, Kipervasser S, Andelman F, Neufeld MY, Kramer U, Arieli A, Fried I, Malach R (2008) Interhemispheric correlations of slow spontaneous neuronal fluctuations revealed in human sensory cortex. Nat Neurosci 11:1100-1108. CrossRef Medline

Oostenveld R, Fries P, Maris E, Schoffelen JM (2011) FieldTrip: open source software for advanced analysis of MEG, EEG, and invasive electrophysiological data. Comput Intell Neurosci 2011:156869. CrossRef Medline

Power JD, Cohen AL, Nelson SM, Wig GS, Barnes KA, Church JA, Vogel AC, Laumann TO, Miezin FM, Schlaggar BL, Petersen SE (2011) Functional network organization of the human brain. Neuron 72:665-678. CrossRef Medline

Power JD, Barnes KA, Snyder AZ, Schlaggar BL, Petersen SE (2012) Spurious but systematic correlations in functional connectivity MRI networks arise from subject motion. Neuroimage 59:2142-2154. CrossRef Medline

Pruim RH, Mennes M, van Rooij D, Llera A, Buitelaar JK, Beckmann CF (2015) ICA-AROMA: a robust ICA-based strategy for removing motion artifacts from fMRI data. Neuroimage 112:267-277. CrossRef Medline

Raichle ME (2015) The restless brain: how intrinsic activity organizes brain function. Philos Trans R Soc Lond B Biol Sci 370:20140172. CrossRef Medline 
Raichle ME, MacLeod AM, Snyder AZ, Powers WJ, Gusnard DA, Shulman GL (2001) A default mode of brain function. Proc Natl Acad Sci U S A 98:676-682. CrossRef Medline

Ray S, Maunsell JH (2011) Different origins of gamma rhythm and highgamma activity in macaque visual cortex. PLoS Biol 9:e1000610. CrossRef Medline

Roland JL, Snyder AZ, Hacker CD, Mitra A, Shimony JS, Limbrick DD, Raichle ME, Smyth MD, Leuthardt EC (2017) On the role of the corpus callosum in interhemispheric functional connectivity in humans. Proc Natl Acad Sci U S A 114:13278-13283. CrossRef Medline

Schölvinck ML, Maier A, Ye FQ, Duyn JH, Leopold DA (2010) Neural basis of global resting-state fMRI activity. Proc Natl Acad Sci U S A 107:1023810243. CrossRef Medline

Schrouff J, Perlbarg V, Boly M, Marrelec G, Boveroux P, Vanhaudenhuyse A, Bruno MA, Laureys S, Phillips C, Pélégrini-Issac M, Maquet P, Benali H (2011) Brain functional integration decreases during propofol-induced loss of consciousness. Neuroimage 57:198-205. CrossRef Medline

Seeley WW, Menon V, Schatzberg AF, Keller J, Glover GH, Kenna H, Reiss AL, Greicius MD (2007) Dissociable intrinsic connectivity networks for salience processing and executive control. J Neurosci 27:2349-2356. CrossRef Medline

Shine JM, Kucyi A, Foster BL, Bickel S, Wang D, Liu H, Poldrack RA, Hsieh LT, Hsiang JC, Parvizi J (2017) Distinct patterns of temporal and directional connectivity among intrinsic networks in the human brain. J Neurosci 37:9667-9674. CrossRef Medline

Shmuel A, Leopold DA (2008) Neuronal correlates of spontaneous fluctuations in fMRI signals in monkey visual cortex: implications for functional connectivity at rest. Hum Brain Mapp 29:751-761. CrossRef Medline

Smith SM, Fox PT, Miller KL, Glahn DC, Fox PM, Mackay CE, Filippini N, Watkins KE, Toro R, Laird AR, Beckmann CF (2009) Correspondence of the brain's functional architecture during activation and rest. Proc Natl Acad Sci U S A 106:13040-13045. CrossRef Medline

Tagliazucchi E, Laufs H (2014) Decoding wakefulness levels from typical fMRI resting-state data reveals reliable drifts between wakefulness and sleep. Neuron 82:695-708. CrossRef Medline
Tavor I, Parker Jones O, Mars RB, Smith SM, Behrens TE, Jbabdi S (2016) Task-free MRI predicts individual differences in brain activity during task performance. Science 352:216-220. CrossRef Medline

Thompson GJ, Merritt MD, Pan WJ, Magnuson ME, Grooms JK, Jaeger D, Keilholz SD (2013) Neural correlates of time-varying functional connectivity in the rat. Neuroimage 83:826-836. CrossRef Medline

Van Dijk KR, Sabuncu MR, Buckner RL (2012) The influence of head motion on intrinsic functional connectivity MRI. Neuroimage 59:431-438. CrossRef Medline

Vincent JL, Patel GH, Fox MD, Snyder AZ, Baker JT, Van Essen DC, Zempel JM, Snyder LH, Corbetta M, Raichle ME (2007) Intrinsic functional architecture in the anaesthetized monkey brain. Nature 447:83-86. CrossRef Medline

Vincent JL, Kahn I, Snyder AZ, Raichle ME, Buckner RL (2008) Evidence for a frontoparietal control system revealed by intrinsic functional connectivity. J Neurophysiol 100:3328-3342. CrossRef Medline

Voytek B, Canolty RT, Shestyuk A, Crone NE, Parvizi J, Knight RT (2010) Shifts in gamma phase-amplitude coupling frequency from theta to alpha over posterior cortex during visual tasks. Front Hum Neurosci 4:191. CrossRef Medline

Wang L, Saalmann YB, Pinsk MA, Arcaro MJ, Kastner S (2012) Electrophysiological low-frequency coherence and cross-frequency coupling contribute to BOLD connectivity. Neuron 76:1010-1020. CrossRef Medline

Winder AT, Echagarruga C, Zhang Q, Drew PJ (2017) Weak correlations between hemodynamic signals and ongoing neural activity during the resting state. Nat Neurosci 20:1761-1769. CrossRef Medline

Worsley KJ, Liao CH, Aston J, Petre V, Duncan GH, Morales F, Evans AC (2002) A general statistical analysis for fMRI data. Neuroimage 15:1-15. CrossRef Medline

Yeo BT, Krienen FM, Sepulcre J, Sabuncu MR, Lashkari D, Hollinshead M, Roffman JL, Smoller JW, Zöllei L, Polimeni JR, Fischl B, Liu H, Buckner RL (2011) The organization of the human cerebral cortex estimated by intrinsic functional connectivity. J Neurophysiol 106:1125-1165. CrossRef Medline 